\title{
Desafios da docência: reflexões a partir da vivência em um curso de graduação em medicina
}

\author{
Teaching challenges: reflections from the experience in a medicine course \\ Graciela Soares Fonseca ${ }^{1}$ (D), Paulo Roberto Barbato² (D), Margarete Dulce Bagatini ${ }^{3}$
}

\begin{abstract}
RESUMO
Introdução: Os novos cursos de medicina demandam inovações pedagógicas e curriculares que intensificam os desafios da prática docente. Objetivo: $O$ trabalho objetiva apresentar os desafios da docência em um curso de graduação em medicina, viabilizado pelo Programa Mais Médicos, a partir da narrativa de três professores. Metodologia: Trata-se de um relato de experiência construído a partir de narrativas reflexivas redigidas livremente por cada um dos docentes, em momento único, no primeiro semestre de 2019. Elas foram sistematizadas e organizadas por um dos autores. Resultados: Dois dos docentes são graduados em odontologia, com pós-graduação na área de saúde coletiva, participando dos oito Componentes Curriculares Regulares (CCR) ligados à essa área. A terceira docente é farmacêutica, com pós-graduação em Ciências Biológicas e compõe os componentes de Processos Biológicos III e IV e Temas Emergentes na Formação Médica 3. As narrativas revelam o quanto o cenário da educação médica é singular e gerador de desafios próprios. O modelo contra-hegemônico do referido curso de medicina gera insegurança para os atores envolvidos, sobretudo pela ausência de referencial comparativo. Além disso, a construção do curso demanda energia extra, visto que se parte do zero para organização de todas as demandas. O uso de metodologias ativas de aprendizagem constitui outro desafio, uma vez que os docentes foram formados sob a ótica do modelo tradicional. Outro aspecto apontado como desafiador pelos três docentes - chamando atenção para o fato de nenhum deles ser médico - é apresentar formação de graduação em outros cursos da área da saúde e o quanto isso causa incompreensões e resistências, manifestada por estudantes e colegas docentes. Por fim, no contexto atual de exercício da docência, o uso intenso de dispositivos tecnológicos foi apontado pelos docentes como um desafio, talvez o mais complexo deles já que seu uso é massivo e é complexo "competir" e organizar uma aula que seja atrativa a ponto de fazer com os estudantes se "desconectem" para se concentrar no que está sendo trabalhado. Conclusão: Conclui-se que a docência em cursos de medicina, em especial naqueles orientados pelas novas DCN, apresenta desafios variados que precisam ser compreendidos e contornados para propiciar uma prática exitosa.
\end{abstract}

Palavras-chave: Docência; Ensino Superior; Medicina; Educação Superior.

\begin{abstract}
Introduction: The new medical courses demand pedagogical and curricular innovations that intensify the challenges of the teaching practice. Objective: This work presents the challenges of teaching in an undergraduate medical course, made possible by the Mais Médicos Program, based on the narrative of three professors. Methodology: it is an experience report from reflective narratives written by each professional in the first term of 2019. They were systematized and organized by one of the authors. Results: Two of the professors are graduated in dentistry, with postgraduate studies in the area of collective health, participating in eight regular curriculum component components linked to this area. The third professor is a pharmacist, with a postgraduate degree in Biological Sciences and composes the components of Biological Processes III and IV and Emerging Themes in Medical Education 3. The narratives reveal how the current scenario is unique and what the current problem is. The counter-hegemonic model of the medical course generates insecurity for the actors involved, mainly due to the lack of comparative reference. Also, the construction of the course requires extra energy since it starts from zero to organize the demands. The use of active learning methodologies is another challenge since the documents were formed from the perspective of the traditional model. Another aspect pointed out as challenging by the three professors - calling attention to the fact that none of them are doctors - is the graduation training in other courses in the health area and the extent to which this causes misunderstandings and resistance, revealed by students and doctors. Finally, in the current context of teaching, the intensive use of technological devices has been addressed by professors as a challenge, perhaps the most complex of them since its use is massive and it is hard to "compete" with it and organize the lessons to be attractive to make students "disconnect" from it to focus on what is being done. Conclusion: It was concluded that teaching in medical courses, especially in those guided by DCN, presents varied challenges that require understanding and circumvented to provide a successful practice.
\end{abstract}

Keywords: Teaching; Higher Education; Medicine; Education, Medical.

Professora Adjunta, curso de Medicina, Universidade Federal da Fronteira Sul (UFFS), Chapecó (SC), Brasil.

Professor Adjunto, curso de Medicina, Universidade Federal da Fronteira Sul (UFFS), Chapecó (SC), Brasil.

Professora Associada, curso de Medicina, Universidade Federal da Fronteira Sul (UFFS), Chapecó (SC), Brasil.

$\bowtie$ Graciela Soares Fonseca. Rodovia SC-484 - km 2, Bloco dos Professores, sala 317. CEP: 89815-899. Chapecó (SC), Brasil. graciela.fonseca@uffs.edu.br | Recebido em: 14/07/2020 | Aprovado em: 25/08/2020 


\section{INTRODUÇÃO}

A concepção de que "quem sabe, automaticamente sabe ensinar", entendendo o ato de ensinar como sinônimo de ministrar aulas expositivas ou palestras sobre temas específicos dominados pelo "professor", predominou na educação superior, em diversas partes do mundo, por um longo período de tempo ${ }^{1}$. No entanto, ser um bom profissional na área de formação não é suficiente para habilitar alguém como docente 2 .

Ainda hoje, a despeito de todas as discussões que envolvem a necessidade de inovação no modelo de ensino-aprendizagem, muitos docentes, em especial aqueles inseridos no ensino superior, seguem o modelo pedagógico tradicio$\mathrm{nal}^{3}$. Os docentes acabam propagando métodos e práticas incoerentes com as demandas dos estudantes, gerando desmotivação e queixas, contribuindo de maneira incipiente para o avanço das práticas educativas ${ }^{4}$.

No entanto, as transformações do mundo contemporâneo, especialmente a evolução tecnológica, vem demandando um perfil docente diferente, exigindo qualificação própria que não pode ser restrita à experiência no exercício da profissão ou, ainda, ao diploma de bacharel, mestre ou doutor na área de formação. Em outras palavras, o professor, para muito além de ser um especialista na área de ensino, deve assumir o papel de mediador da aprendizagem ${ }^{1}$, permitindo que 0 estudante ocupe o centro do processo, tornando-se parceiro do professor ${ }^{5}$. A mediação pedagógica consiste na postura de facilitador ou incentivador adotada pelo docente, convertendo-se em uma ponte entre $\mathrm{o}$ aprendiz e sua aprendizagem ${ }^{1}$.

De uma preocupação total e exclusivamente voltada para a transmissão de informações e experiências, iniciou-se um processo de buscar o desenvolvimento da aprendizagem dos alunos; de aperfeiçoar sua capacidade de pensar; de dar um significado para aquilo que era estudado, de perceber a relação entre o que o professor tratava em aula e sua atividade profissional; de desenvolver a capacidade de construir seu próprio conhecimento, desde coletar informações até a produção de um texto que revele esse conhecimento ${ }^{1, p .20}$.
O profissional precisa ser competente e habilidoso em sua área de atuação, mas, a sociedade também exige que ele seja um cidadão responsável pelo desenvolvimento da comunidade onde irá atuar. Essa conjuntura levou os currículos à agregarem o envolvimento com a realidade no período de formação, bem como a inclusão de discussões relacionadas aos valores éticos, sociais, políticos e econômicos, "por ocasião do estudo de problemas técnicos, integrando-se à análise teórico-técnica de determinada situação com os valores humanos e ambientais presentes e decorrentes de solução técnica apresentada ${ }^{1, p .20}$, o que aumenta, ainda mais, os desafios da prática docente.

No que tange à formação médica, as mudanças contemporâneas materializadas, sinteticamente, nas Diretrizes Curriculares Nacionais (DCN) de 20146, em detrimento à formação tecnicista, biologicista e hospitalocêntrica que predominou ao longo dos anos, requerem um médico generalista, crítico, reflexivo, comprometido socialmente e integrado à realidade onde irá atuar. Essa conjuntura vem imprimindo novas demandas para a docência na área médica, seja na compreensão de que o docente especialista técnico não é suficiente para alcançar esse perfil, seja no entendimento de que o modelo de ensino-aprendizagem precisa ser ativo e integrado à realidade.

Nesse contexto, os desafios para os docentes vinculados ao curso de medicina da Universidade Federal da Fronteira Sul (UFFS), campus Chapecó - implantado em 2015 em função da aprovação de vagas pelo Programa Mais Médicos (PMM) 7 e organizado com base nas DCN de $2014^{6}$ - são numerosos, intensos e, por vezes, desconhecidos, revelando-se a partir do cotidiano de trabalho no curso. Assim, o manuscrito objetiva apresentar e discutir esses desafios a partir da narrativa de três professores vinculados ao curso.

\section{METODOLOGIA}

Trata-se de um relato de experiência construído a partir das narrativas reflexivas de três $(n=03)$ docentes vinculados ao curso de medicina citado anteriormente. As narrativas foram redigidas livremente por cada um dos docentes, em momento único, no primeiro semestre de 2019, partindo 
do princípio de que, ao narrar os percursos na docência, os professores poderiam ressignificar as experiências vividas e construir conhecimentos a partir delas ${ }^{8-10}$.

Com relação à formação e a área de atuação dentro do curso, dois dos docentes são graduados em odontologia, com pós-graduação na área de saúde coletiva, participando dos oito (08) Componentes Curriculares Regulares (CCR) ligados à essa área (DC-01 e DC-02). A terceira docente é farmacêutica, com pós-graduação em Ciências Biológicas - Bioquímica Toxicológica - e compõe os CCR de Processos Biológicos III, Processos Biológicos IV e Temas Emergentes na Formação Médica 3 - Tópicos em Toxicologia Clínica (DC-03).

As narrativas foram sistematizadas e organizadas, por um dos autores, de acordo com as seguintes categorias de análise: 1) Novo formato de curso, 2) Competências pedagógicas para o trabalho com Metodologias Ativas de Aprendizagem e 3) Ser não-médico na formação médica.

Os recortes das narrativas que serão apresentados no tópico a seguir encontram-se em primeira pessoa do singular com vistas a preservar 0 sentido original impresso pelos narradores. A versão final do texto foi revista por todos os autores no intuito de "validar" os significados e as interpretações realizadas.

\section{RESULTADOS E DISCUSSÃO}

\section{Novo formato de curso}

Dois dos professores iniciaram a redação das narrativas relatando, brevemente, o percurso triIhado na docência antes de chegar à Instituição de Educação Superior (IES) e ao curso em que estão vinculados hoje.

"A docência sempre foi um de meus objetivos durante o curso de graduação, porém circunstâncias fizeram com que adiasse este objetivo. Após mais de 10 anos atuando em atendimento clínico, decidi que seria o momento de voltar a me qualificar, buscando essa meta. Então, em 2010, durante meu período de doutorado, fui selecionado como professor substituto na Universidade Federal de Santa Catarina para trabalhar com os cursos de medicina, odontologia e nutrição, em disciplinas de conteúdos de epidemiologia e bioestatística (para nutrição e odontologia) e atividades de inserção de estudantes nos serviços de saúde em Florianópolis (medicina). Esse preâmbulo é somente para aproximar a realidade que encontrei ao me inserir no curso de Medicina da Universidade Federal da Fronteira Sul, no ano de 2016. Estava voltando para a docência, agora como professor concursado em uma universidade nova e em um curso em implantação. Será que a experiência prévia me daria respaldo frente à nova situação?" (DC-01).

"Antes de começar a trabalhar aqui, eu tive algumas experiências como docente: ministrei aulas de reforço para estudantes do ensino fundamental e médio, fui monitora durante a graduação, colaborei com disciplinas de Saúde Coletiva para o curso de odontologia da Universidade de São Paulo durante minha pós-graduação, e fui professora de um curso de auxiliar de saúde bucal, além de atuar como tutora de cursos de Educação à Distância. Em todos esses contextos, vivi situações desafiadoras, mas nenhuma delas foi tão intenso quanto o que vivo hoje. " (DC-02).

A motivação dos professores para relatar a trajetória na docência consiste em uma necessidade de comparar o atual contexto com experiência anteriores, frisando o quanto o cenário atual é singular e gerador de desafios próprios.

O modelo contra-hegemônico do referido curso de medicina, alinhado às novas DCN para a formação médica ${ }^{6}$ gera insegurança para os atores envolvidos, sobretudo pela ausência de referencial comparativo. Além disso, a construção do curso demanda energia extra, visto que parte-se do zero para organização de todas as demandas.

"Desde que iniciei minhas atividades no curso de medicina da UFFS, campus Chapecó, venho me surpreendendo com a quantidade de desafios que surgem no cotidiano da docência" (DC-02).

"Diferentemente de escolas médicas já consolidadas, estamos no processo da construção de um 
curso de medicina novo, baseado nas mais recentes diretrizes curriculares nacionais e demandado pelo Programa Mais Médicos. Esse processo por si é um gerador de insegurança, considerando todas as possibilidades que porventura possam influenciar no reconhecimento do curso. Além desse aspecto, por ser novo, tudo está por ser criado, aplicado, avaliado e redefinido (caso avaliado negativamente). E mudanças de maneira geral geram insegurança" (DC-01).

Em consonância com as novas DCN, o Projeto Pedagógico Curricular (PPC) do curso coloca a Saúde Coletiva, compreendida como um campo de saberes e práticas, como o eixo transversal da estrutura curricular, devendo facilitar a integração de conteúdos e temas trabalhados no sentido de permitir que os estudantes construam as competências requeridas pelo trabalho em saúde na lógica da integralidade. Além disso, na matriz curricular, há Componentes Curriculares Regulares (CCR) específicos para trabalhar o conteúdo formal de Saúde Coletiva, distribuídos em todo o período de curso pré-internato (Saúde Coletiva I a VIII) ${ }^{11}$.

No entanto, a despeito de toda a potencialidade desse modelo no sentido de formar médicos com perfil mais próximo das demandas sociais, as narrativas dos docentes revelam os desafios e as resistências geradas a partir dessa proposta:

"Quando eu li o edital do concurso da UFFS, que selecionaria sete vagas para docentes de saúde coletiva, com formações variadas, fui atraída pela possibilidade de trabalho interprofissional em um curso de medicina formatado a partir das novas DCN. Ao chegar, me deparei com um curso em construção e muitas incertezas. Sabia que a Saúde Coletiva, como um CCR, estaria presente na matriz curricular da primeira a oitava fase do curso e, ao mesmo tempo que enxergava isso como avanço em direção à formação coerente com as necessidades sociais, me desesperava por não compreender muito bem como os CRR iam funcionar" (DC-02).

Os estudantes, em grande número, ingressam no curso com o imaginário do modelo formador biomédico, hiperespecializado e hospitalocêntrico ${ }^{12}$.
Ao encontrar a realidade de um curso com um modelo diferente, eles tendem a se frustrar e, em alguns casos, mostram resistência para aprendizagem daquilo que, no julgamento deles, não é essencial para a prática médica.

"[...] o estudante, de maneira geral, chega à graduação com seu imaginário construído que no primeiro semestre já vai estar praticando a profissão, acompanhando casos, realizando procedimentos, prescrevendo, enfim, atuando como profissional. Acredito que esse desafio será a perspectiva permanente do ensino na área da saúde (e por que não nas demais). Como lidar com essa ansiedade, sem frustrar as expectativas criadas no imaginário do estudante?" (DC-01).

"Então, por conta disso é que vejo esse desafio como um dos permanentes na formação universitária e para os docentes: mitigar a ansiedade dos estudantes sem provocar desânimo ou desapontamento com a carreira escolhida" (DC-01).

"Foi aí que os desafios começaram a aparecer. Sem dúvidas, o mais difícil é a resistência dos estudantes. Boa parte deles entra no curso com o imaginário social do modelo biomédico e supervalorizam especialidades, técnicas e procedimentos. Não faz muito sentido pra eles as discussões propostas pela saúde coletiva. Alguns entram em sofrimento por não se identificar com o perfil do curso. Trabalhar nesse contexto é complicado e exige criatividade para se adaptar e se reinventar com o intuito de cativar os estudantes e mostrar a importância desse conhecimento para a formação" (DC-02).

Especificamente no que se refere aos CCR de Saúde Coletiva, a resistência é intensificada em função da confusão existente entre a construção de conhecimentos sobre políticas públicas de saúde e uma possível "doutrinação ideológica". Os trechos que seguem ilustram essa colocação:

"Trabalhar com a temática da saúde coletiva e todos os aspectos complexos que a constituem, como dito anteriormente, pode ser mais penoso e desafiador quando há uma descontextualização 
da mesma. Acredito que é impossível falar de saúde coletiva sem articulá-la ao contexto socioeconômico e cultural, seja ele nacional ou regional. Também não entendo como discutir política pública sem contextualizar o momento histórico que a antecedeu e aquele que a levou ao debate e a fez prosperar. Esse arcabouço construído muitas vezes é entendido por alguns estudantes como uma doutrinação ideológica, já que a crítica e a reflexão sobre os momentos históricos parecem ser desnecessários para entender o sistema em que vivemos. Que tratar das lutas sociais e os avanços nas políticas públicas que estas produziram é ser um 'esquerdopata-comunistadoutrinador'" (DC-01).

"Como a Saúde Coletiva é um campo de saberes e práticas voltado para a defesa da saúde como um direito universal, os conteúdos precisam ser trabalhados de modo crítico e contextualizado com a conjuntura política e econômica do país. Em alguns momentos, isso já foi confundido com discussão político-partidário e gerou reações intempestivas e acusatórias em sala de aula, o que foi bem constrangedor" (DC-02).

"Lembro-me de uma situação, em que eu mediava uma aula sobre clínica ampliada e produção do cuidado para a $4^{a}$ fase, quando um estudante ficou muito nervoso e gritou que tinha ódio de tudo aquilo. Quando abrimos para que ele pudesse se colocar de modo mais claro, ele afirmou que essas "coisas" não tradicionais o incomodavam porque o sonho dele estava sendo destruído e que ele não gostava de política. Só pra ilustrar um pouco" (DC-02).

Além disso, ressalta-se que o professor é um cidadão e, como tal, deverá estar atento ao que ocorre na sociedade, suas transformações, mudanças, evoluções, conquistas, valores emergentes, descobertas e novas proposições. É necessário abrir espaço para essas discussões em sala de aula tendo em vista que a atuação futura dos profissionais deverá ser coerente com essa realidade e que essas características irão afetar o exercício profissional ${ }^{1}$.
Competências pedagógicas para o trabalho com Metodologias Ativas de Aprendizagem

Seguindo a legislação vigente, o PPC do curso de medicina analisado coloca a abordagem construtivista da educação, com estímulo ao uso de Metodologias Ativas de Aprendizagem (MAA), no centro dos processos pedagógicos ${ }^{11}$. As MAA facilitam a interação dos estudantes com os objetos de estudo, o que propicia a construção de conhecimento de modo ativo, em detrimento do recebimento de informações de maneira pacífica e acrítica ${ }^{13}$.

Criar condições de ter uma participação mais ativa dos alunos implica, absolutamente, a mudança da prática e o desenvolvimento de estratégias que garantam a organização de um aprendizado mais interativo e intimamente ligado com as situações reais. Por isso, a inovação na educação é essencialmente necessária. A inovação é uma das formas de transformar a educação ${ }^{14, \text { p.4 }}$.

No entanto, para os docentes, mesmo entendendo que já não é possível ensinar e aprender utilizando metodologias de ensino pautadas na transmissão de conteúdo, o uso de estratégias ativas de aprendizagem constitui um desafio como apontam os recortes que seguem:

"Por não ser um profissional que cursou licenciatura $[. .$.$] , sinto que preciso aprender durante o pro-$ cesso e tenho me inserido nas atividades de qualificação pedagógica para poder entender como lidar com essa ansiedade e dar a resposta aos estudantes de maneira adequada às suas necessidades. Evidentemente que sem abrir mão dos pressupostos da formação universitária, sempre ressaltando que as atividades propostas têm um sentido pedagógico e que não adianta darmos longos passos sem construirmos um caminho trilhado, que deverá ser o norte para os que virão depois" (DC-01).

"Além disso, nas aulas teóricas, ainda é um desafio enorme trabalhar de modo ativo e participativo. Percebo que, com o tempo, tenho conseguido melhorar isso, sobretudo, porque tive algumas 
oportunidades de formação que me deixaram um pouco mais segura e fui aprendendo com a própria experiência. No entanto, cabe a reflexão do quanto a nossa formação para o trabalho docente é incipiente" (DC-02).

Outros trabalhos vêm mostrando as dificuldades dos docentes para se adaptar ao modelo de ensino ativo ${ }^{15,16}$.

É necessário considerar que o processo de ensino-aprendizagem é algo extremamente complexo, possui caráter dinâmico e não acontece de forma linear, exigindo ações direcionadas, para que os alunos possam se aprofundar e ampliar os significados elaborados mediante sua participação. Ao apostar em uma nova concepção de ensino, evidentemente, deve-se pensar em uma prática pedagógica capaz de garantir aos alunos uma aprendizagem sólida, que Ihes permita enfrentar criticamente as mudanças da atual sociedade da informação e do conhecimento. Para que o estudante assuma uma postura mais ativa e, de fato, se descondicione da atitude de mero receptor de conteúdos e busque efetivamente conhecimentos relevantes aos problemas e aos objetivos da aprendizagem, os processos educativos devem acompanhar as mudanças ${ }^{14,}$ p.10.

Intensificando a problemática da incorporação de estratégias ativas de ensino, as turmas do referido curso são formadas por perfis diversificados e estudantes. Como o ingresso na IES é realizado via Sistema de Seleção Unificada (SISU), há estudantes de diversas regiões do país. Além disso, eles divergem em idade, objetivos pessoais e profissionais e alguns já tiveram experiências anteriores de formação de nível superior. O desafio se torna maior uma vez que "uma só forma de trabalho pode não atingir a todos os alunos na conquista de níveis complexos de pensamento e de comprometimento em suas ações, como desejados, ao mesmo tempo e em curto tempo"17, p.37, requerendo que o professor tenha um conhecimento aprofundado do perfil de cada turma e organize as aulas, de modo singular, para cada uma delas.

"Outro ponto desafiador na prática docente é nos adaptarmos aos diferentes perfis de turma.
Muitas atividades que funcionam com uma turma não funcionam com outra e essa sensibilidade é de fundamental importância, para não propormos atividades que não atinjam seus objetivos. Os diferentes perfis de turma ocorrem pelas diferenças de idade e também porque as turmas são formadas por discentes das mais diferentes regiões do país" (DC-03).

Estratégias pedagógicas estruturadas em pequenos grupos são fundamentais no sentido de viabilizar os objetivos de um ensino ativo. A aprendizagem cooperativa contribui para aumentar o rendimento, a motivação e autoestima dos estudantes, além de favorecer maior aceitação dos diferentes perfis de coletas e contribuir para o desenvolvimento de interdependência positiva ${ }^{18}$. $O$ ensino em pequenos grupos contribui para potencializar a criatividade dos estudantes, aumentar sua capacidade de solucionar problemas e desenvolver pensamento crítico ${ }^{19}$.

Entretanto, a concretização do ensino colaborativo em pequenos grupos também imprime desafios para a prática docente:

"[...] Sendo que essas diferenças entre as turmas se refletem na competitividade que existe entre os discentes. Percebo que turmas mais competitivas não trabalham bem com atividades coletivas, como seminários e apresentação de trabalho em grupo e, portanto permanece a dúvida: devemos mesmo assim propor essas atividades? Será que elas atingirão seus objetivos? Ou deveríamos excluí-las?" (DC-03).

O estudo de Conceição e Moraes ${ }^{16}$, cujos participantes foram estudantes de graduação em medicina de uma IES que adota métodos ativos de ensino-aprendizagem, revelou que, apesar de reconhecer a presença de competitividade entre colegas quando do trabalho em pequenos grupos, o sentimento de cooperação predomina em relação à competição. No entanto, quando a análise era restrita à turma que ingressou mais recentemente no curso, o sentimento de competição era prevalente.

No caso específico dos CCR de Saúde Coletiva, além das atividades de grupo desenvolvidas durante as aulas teóricas, parte da carga horária é desenvolvida com os estudantes organizados em grupos tutoriais, acompanhados por um docente: sãos os 
grupos de ensino com pesquisa e/ou extensão e as atividades práticas de integração com os serviços de saúde e a comunidade.

O trecho que segue explicita os detalhes da estratégia de ensino com pesquisa e/ou extensão e evidencia os desafios derivados da implantação dessa estratégia inovadora no PPC do curso:

"Ainda compondo parte da carga horária de alguns dos CCR de Saúde Coletiva, estão previstas atividades de ensino com pesquisa ou extensão. Em pequenos grupos, com a tutoria de um docente, os estudantes participam da construção e desenvolvimento de projetos de pesquisa e extensão. No início, apesar de estar previsto no PPC, nenhum docente sabia muito bem como essa atividade deveria funcionar. Tudo foi se organizando com base em erros e acertos e, paralelamente, recebemos muitas críticas dos estudantes e de outros colegas docentes. Conseguimos estudar, buscar experiências parecidas em outras instituições e "aprender" um pouco mais sobre essa estratégia pedagógica sendo que, hoje, o desafio é menor, mas ainda existe" (DC-02).

Ainda, especificamente no que se refere à organização tutorial de parte da carga horária dos CCR de Saúde Coletiva, há desafios que, normalmente, não aparecem quando se trabalha com a turma completa:

"Estar inserida em todos os CCR de Saúde Coletiva (I a VIII) também gera desafios. São atividades diversificadas que agregam uma série de temas, muitas vezes, desenvolvidas em pequenos grupos, exigindo muito planejamento o que, por sua vez, demanda o tempo que não temos. Em função da estratégia de ensino com pequenos grupos de estudantes, preciso trabalhar em sintonia com os demais docentes de saúde coletiva. Por sermos diferentes em muitos aspectos, trabalhar em grupo nem sempre é tranquilo. Toda organização que temos hoje foi construída nesse grupo, com muita discussão, alguns conflitos e muita energia dispensada. Quase nunca posso tomar decisões sozinha, sem a ciência ou concordância da maioria, o que, em alguns momentos, é desgastante (CD-02).
No que se refere às atividades práticas de inserção na Rede de Atenção à Saúde (RAS), exigência das DCN para a graduação em medicina ${ }^{6}$, os desafios vão além da competência pedagógica, demandando do docente criatividade, disposição e abertura ao novo, capacidade de diálogo e articulação com a RAS e a gestão municipal de saúde, além de preparo para lidar com imprevistos:

"Nesse sentido, também é desafiador conseguir envolver os estudantes nas atividades propostas na rede de saúde, onde sua imersão tem a finalidade de vivenciar as experiências do "mundo real" articulando-as com os conceitos teóricos do componente curricular. Sair do ambiente protegido da sala de aula para um centro de saúde da família e entender a realidade pode ser algo gratificante ao extremo, ou causador de desgastes emocionais severos, uma vez que nem sempre o planejado é possível de acontecer. A realidade cotidiana dos serviços de saúde pode "engolir" o planejamento das atividades, causando frustrações tanto nos estudantes quanto no docente, restando uma sensação de tempo perdido por parte daqueles e de fragilidade e impotência por este" (DC-01).

"Os CCR de Saúde Coletiva desenvolvem atividades práticas em serviços de saúde da Rede de Atenção à Saúde (RAS) de Chapecó. Sair da protegida sala de aula para um espaço externo, com atores diferentes, representa outro desafio. Em um serviço de saúde real, os imprevistos acontecem o tempo inteiro e é impossível controlar todas as variáveis que podem interferir nas nossas atividades, exigindo de nós uma capacidade de adaptação, jogo de cintura, e criatividade gigantescas para lidar com as adversidades dos espaços externos e manter a atuação docente de modo satisfatório" (DC-02).

"Para que as atividades se concretizem, precisamos pactuar as atividades com a secretaria de saúde, bem como planejar conjuntamente com a coordenação do serviço e "negociar" as inserções e ações com todos os membros das equipes de saúde. Em alguns momentos, essa tarefa é difícil visto que a compreensão da formação em serviço ainda é pequena para muitos profissionais da RAS e, 
somos vistos - docentes e estudantes - como pessoas que atrapalham a rotina dos serviços. Apesar de toda a potência formativa dessa prática, mediar a construção de conhecimentos em um contexto desses, é bem complicado" (DC-02).

No âmbito das competências pedagógicas para a docência na formação médica, o uso intenso de dispositivos tecnológicos pelos estudantes foi apontado pelos docentes como um desafio, talvez, o mais complexo deles já que seu uso é massivo e é complexo "competir" e organizar uma aula que seja atrativa a ponto de fazer com os estudantes se "desconectem" para se concentrar ao que está sendo trabalhado.

"Fazer docência de modo inovador é um desafio, pois precisamos "competir" com as mídias sociais que estão presentes no dia a dia dos jovens e adultos e muitos deles não sabem qual o momento certo de utilizar as mídias ou quanto do seu tempo podem disponibilizar para as mesmas, sendo que cada vez mais estão inseridos e dependes das mais diversas tecnologias" (DC-03).

"Parece evidente que existem ainda muitos desafios na docência, mas quero terminar falando daquele que, ao meu ver, se modificou com grande rapidez nos últimos anos: o uso das ferramentas tecnológicas na sala de aula. Faço essa referência pois, passados sete anos de minha primeira experiência com a docência, é muito perceptível a mudança de comportamento dos estudantes e sua relação com as tecnologias. Claro que em 2011 já existiam computadores portáteis e celulares, mas a forma como os estudantes lidam com essas ferramentas (entre tantas outras disponíveis) é uma realidade muito diferente. Diante das ferramentas e das possibilidades que a inclusão digital propicia, o docente tem que se superar para conseguir executar sua tarefa de compartilhar as experiências e conhecimentos, dialogando com os estudantes e as informações que trazem (muitas vezes equivocadas ou excessivamente rasas) para subsidiar seus posicionamentos. A competição com a tecnologia e o acesso à informação parece demasiadamente injusta" (DC-01).
"E agora? Como participar da formação de profissionais, e acima disso, a formação de cidadãos que já têm contato com todas essas tecnologias antes de nascerem ou ainda muito precocemente? Como tornar uma aula atrativa, quando a concentração perde todo o tempo para a necessidade da interação imediata com uma mensagem que chega via aplicativos? Quando postar seu status atual é uma necessidade quase vital? Não tenho respostas para estes e muitos outros questionamentos que não me ocorrem, só me parece que muitos desafios ainda estão por vir" (DC-01).

Em média, as pessoas verificam seus telefones a cada 12 minutos e um em cada cinco adultos passa mais de 40 horas por semana on-line. Além disso, "Smartphones, mídias sociais, videogames e tempo de tela em geral têm sido acusados de prejudicar a memória, a atenção e a leitura, tornando-nos menos sociáveis, civilizados e empáticos". Trata-se do Homem Vitruviano moderno: totalmente conectado e ligado a diversos equipamentos (Figura 1) ${ }^{20}$.

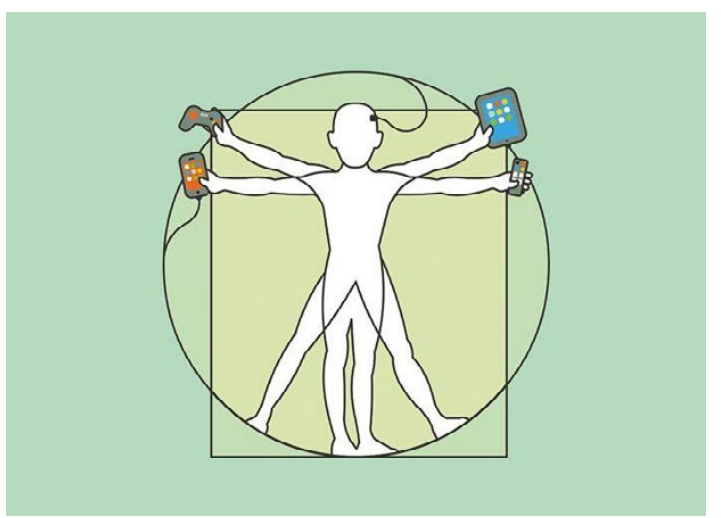

Figura 1. Homem Vitruviano moderno.

Fonte: Nature, 2018.

Ou seja, as tecnologias digitais fazem parte do cotidiano do mundo contemporâneo, no entanto, a incorporação delas no processo de ensino-aprendizagem se choca com empecilhos diversos como: resistência de parte dos docentes, preparo pedagógico inadequado dos docentes para lidar com essas tecnologias e a estrutura física inadequada ${ }^{21}$. Apesar dos expressivos avanços tecnológicos dos 
últimos anos, predominam, em todos níveis de ensino, aulas tradicionais sendo o giz, o caderno e a caneta substituídos por outros dispositivos que ocupam o mesmo papel: favorecer a transmissão de conteúdo e a memorização deles pelos estudantes $^{14}$. As tecnologias digitais ocupam o lugar de ferramentas de suporte e devem ser inseridas em consonância com os objetivos do processo educativo ${ }^{21}$.

Muitos confundem a modernização com a metodologia ativa de aprendizagem. Apesar do recurso tecnológico, salas de aula com lousas eletrônicas podem reforçar ou manter relações verticais, contribuindo para a consagração do professor como um repassador (até com boas habilidades) de informações, mantendo o aluno na perspectiva de memorizador e de reprodutor fidedigno de conhecimento. O uso de tecnologias não é metodologia ativa de aprendizagem ${ }^{3, p .16}$.

A estratégia utilizada pelos docentes tem sido aliar as tecnologias às estratégias metodológicas utilizadas em sala de aula:

"Na minha prática docente busco inserir o uso das tecnologias para discutir conteúdos, trabalhar exercícios e realizar revisões de conteúdos. Essa experiência tem se mostrado muito válida, pois o discente trabalha determinados conteúdos de forma dinâmica e utilizando um dispositivo que está adaptado que é o computador ou o telefone celular $[\ldots]^{\prime \prime}(\mathrm{DC}-03)$.

"Nesse momento cabe ao docente usar a situação a seu favor, como estratégia de busca de informação atualizada ou utilizando ferramentas que permitam a interação do estudante com o material de apoio da atividade que esteja desenvolvendo" (DC-01).

\section{Ser não-médico na formação médica}

Outro aspecto apontado como desafiador pelos três docentes - chamando atenção para o fato de nenhum deles ser médico - é apresentar formação de graduação em outros cursos da área da saúde e o quanto isso causa incompreensões e resistências. Nos recortes que seguem, os docentes revelam que os estudantes apresentam resistências porque não conseguem entender como o "saber" de alguém que não exerce a medicina pode ser útil para um futuro médico:

"Por fim, outro desafio que percebo no dia a dia docente é o trabalho do professor não médico trabalhando com futuros médicos. Existe uma resistência muito forte dos discentes aceitarem os professores não médicos por acharem que falta a prática clínica, entretanto, acredito que devemos trabalhar isso de forma efetiva para desconstruir esse paradigma logo nos primeiros semestres do curso. Cada docente está habilitado na sua área de conhecimento e apresenta autonomia docente para trabalhar de diferentes maneiras um mesmo conteúdo. Mas também é recomendando o diálogo com os docentes médicos para que exista uma sintonia no trabalho realizado e os discentes possam sentir segurança em cada docente" (DC-03).

"O fato de não ser médica, em um curso de formação médica, também gera alguns dificultadores para minha prática docente. Para os estudantes, é "estranho" aprender com quem não desenvolve a mesma prática clínica que eles irão desempenhar no futuro. A compreensão de que existe uma clínica do comum e uma área de atuação interprofissional na saúde ainda é distante para a maioria" (DC-02).

"Acredito que os estudantes cheguem a um curso de medicina com a imagem objetivo de um médico bem sucedido, ultra especializado, financeiramente estável e incapaz de errar. Então, para eles (penso eu), estando diante daquele que é sua imagem objetivo tudo o que um docente médico referir passa a ser verdade absoluta. Qualquer coisa em contrário não tem valor ou se trata-se de questão menor. Penso que isso perdure até o momento em que percebem que estão diante de um ser humano, com todas as complexidades inerentes a este e que também é passível de erro. Mas até que esse momento chegue, ser docente não sendo médico é ser confrontado (e algumas vezes afrontado em sua capacidade profissional), considerando aspectos do conhecimento que entendem ser única e exclusivamente 
de competência médica, portanto tornando-se uma heresia um "de fora do grupo" opinar ou demonstrar conhecimento técnico sobre o assunto" (DC-01).

Os docentes revelaram, ainda, a extensão dessa resistência a alguns colegas docentes que, como os estudantes, não conseguem compreender o papel de um docente não médico, sobretudo aqueles que atuam especificamente com Saúde Coletiva, em curso de graduação em medicina.

"É um desafio estar em um curso onde docentes médicos não compreendem a importância da formação em saúde coletiva, desqualificando a área de conhecimento, minimizando sua importância ou ainda ridicularizando sua existência, visto que a formação técnica (na visão destes) deve ser o objetivo precípuo da formação. Nesse aspecto torna-se um desafio maior a afirmação da importância do conhecimento da determinação social envolvida no processo saúde-doença da população; da visão crítica do papel do Estado como garantidor do direito à saúde; a reflexão da vida que nos cerca e o papel do estudante, futuro profissional, nessa sociedade desigual e injusta" (DC-01).

"Outra questão que eu considero muito desafiadora no exercício da docência nesse curso, especificamente, é a pouca compreensão dos colegas docentes sobre o campo de saberes e práticas da saúde coletiva, bem como o papel que ele desempenha dentro do curso. Segundo as DCN para a graduação em medicina, esse campo de saberes e práticas deve ser transversal ao ensino, o que quer dizer, que todos os CCR precisam se ancorar na saúde coletiva para permitir uma formação integrada. No entanto, há um entendimento equivocado de que os CCR Saúde Coletiva seriam os responsáveis por alcançar esses objetivos quando, na verdade, isso seria impossível, sendo esses CCR complementares aos demais. Vivemos episódios de resistência desagradáveis e desmotivadores, mas, acredito que a origem desse problema esteja na "novidade" que o formato do nosso curso representa" (DC-02).
O trabalho em saúde é complexo e, para ser efetivo e alcançar as respostas pretendidas, precisa ser colaborativo de interprofissional. Um só "saber" não é capaz de solucionar os problemas que a população apresenta e a formação "disciplinar" é alvo de críticas por promover uma formação descontextualizada com a realidade futura que será encontrada ${ }^{22-25}$.

\section{CONSIDERAÇÕES FINAIS}

"Concluo essa narrativa afirmando que os desafios se renovam a cada dia, mas o percurso tem sido formativo e enriquecedor, o que me dá mais segurança e confiança para trilhar os próximos passos" (CD-02).

Os desafios inerentes à docência na formação médica são inúmeros e derivam, essencialmente, da mudança de paradigmas na formação e das transformações do mundo contemporâneo. No entanto, a experiência é formativa e, por si só, compreende uma prática de Educação Permanente que guia e apoia os docentes na construção desse curso que além de novo, é inovador.

\section{REFERÊNCIAS}

1. Masetto T. Competência pedagógica do professor universitário. São Paulo: Summus, 2003.

2. Jara-Gutiérrez NP, Díaz-López MM, Zapata-Castañeda PN. Desafíos educativos para el profesor de medicina: evaluación de su desempeño. Iatreia. 2015; 28(3): 292-99.

3. Camargo F. Por que usar metodologias ativas de aprendizagem? In: Camargo F, Daros T. A sala de aula inovadora: estratégias pedagógicas para fomentar o aprendizado ativo. Porto Alegre: Penso, 2018. p. 3-7.

4. Pádua, GD. "Esses professores precisam de reciclagem": a avaliação dos estudantes da UFU sobre as práticas didático pedagógicas dos docentes. Diversa prática. 2012; 1(1): 135-52.

5. Freire P. Pedagogia do oprimido. 47a ed. São Paulo: Paz e Terra; 2008.

6. Brasil. Ministério da Educação (BR). Resolução CNE/CES no $3 / 2014$, de 20 de Junho de 2014. Institui diretrizes curriculares nacionais do curso de graduação em medicina e dá outras providências. Diário Oficial da União. 23 Jun 2014. 
7. Brasil. Presidência da República (BR). Lei no 12.871 , de 22 de Outubro de 2013. Institui o Programa Mais Médicos, altera as leis no 8.745, de 9 de Dezembro de 1993, e no 6.932, de 7 de Julho de 1981, e dá outras providências. Diário Oficial da União. 23 Out 2013.

8. Bondía JL. Notas sobre a experiência e o saber da experiência. Rev Bras Educ. 2002; (19):20-8.

9. Carvalho ICM. Biografia, identidade e narrativa: elementos para uma análise hermenêutica. Horiz Antropol. 2003; 9(19):283-302.

10. Oliveira MCSL. Narrativas e desenvolvimento da identidade profissional de professores. Cad CEDES. 2012; 32(88):369-78.

11. UFFS. Projeto Pedagógico do curso de graduação em medicina - Bacharelado. Chapecó, 2019. Disponível em: https://www.uffs.edu.br/atos-normativos/ppc/ccmech/ 2018-0001 [acesso de 01 de maio de 2019].

12. Feuerwerker LCM. Gestão dos processos de mudança na graduação em medicina. In: Marins JJN, Rego S, Lampert JB, Araújo JGC, organizadores. Educação médica em transformação: instrumentos para a construção de novas realidades. São Paulo: Hucitec; 2004. p. 17-39.

13. Souza DM, Mocelin J, Danielski K, Backes VMS. Entre a alienação e a libertação: da concepção bancária a concepção problematizadora da educação. In: Padro ML, Schimidt KR. A boniteza de ensinar e aprender na saúde. Florianópolis: NFR/UFSC; 2016. p. 37-59.

14. Daros T. Por que inovar na educação? In: Camargo F, Daros T. A sala de aula inovadora: estratégias pedagógicas para fomentar o aprendizado ativo. Porto Alegre: Penso, 2018. p. 3-7.

15. Almeida MTC, Batista NA. Ser docente em métodos ativos de ensino-aprendizagem na formação do médico. Rev Bras Educ Med. 2011;35(4):468-76.

16. Conceição CV, Moraes MAA. Aprendizagem Cooperativa e a Formação do Médico Inserido em Metodologias Ativas: um Olhar de Estudantes e Docentes. Rev Bras Educ Med. 2018; 42(4):115-22.
17. Berbel NAN. As metodologias ativas e a promoção da autonomia de estudantes. Semina Ciênc Sociais E Humanas. 2012; 32(1):25-40.

18. Vega Vaca ML, Vidal Rodriguez D, Del Pilar Garcia M. Avances acerca de los efectos del aprendizaje cooperativo sobre el logro académico y las habilidades sociales en relación com el estilo cognitivo. Rev Colomb Educ. 2013; 64:155-74.

19. Costa MCG, Mazzoni CJ, Braccialli LAD, Moraes MAA. Exercício de avaliação da prática profissional como estratégia de ensino e aprendizagem. Avaliação (Campinas). $2011 ; 16(3)$ : 675-84.

20. Makin, Simon. Searching for digital technology's effects on well-being. Nature, 2018; 563: 138-40.

21. Wanderley TPSP, Batista MHJ, Dutra Júnior LS, Silva VC. Docência em saúde: tempo de novas tecnologias da informação e comunicação. Reciis - Rev Eletron Comun Inf Inov Saúde. 2018; out./dez.;12(4): 488-501.

22. World Health Organization. Framework for Action on Interprofessional Education and Collaborative Practice. [Internet] Genebra: WHO/HRH/HPN/10.3; 2010. [citado 12 jul 2017] Disponível em: http://www.who.int/hrh/ nursing_midwifery/en/.

23. Batista N. A educação interprofissional na formação em saúde. In: Capozzolo AA, Casseto SJ, Henz AO, editores. Clínica comum: itinerários de uma formação em saúde. São Paulo: Hucitec; 2013. p.59-68.

24. Peduzzi M, Norman IJ, Germani ACCG, Silva JAM, Souza GC. Educação interprofissional: formação de profissionais de saúde para o trabalho em equipe com foco nos usuários. Rev esc enferm. 2013; 47(4): 977-83.

25. Fonseca GS, Junqueira SR, Botazzo C, Araujo ME. Da fragmentação à formação interprofissional: proposta de um modelo de estágio curricular supervisionado para a graduação em odontologia. Saúde em Redes. $2017 ; 3$ (4):410-424. 